\title{
Evaluation of Anti-Hyperglycaemic Potential of Allium Cepa, Coffee and Oxidative Stress
}

\section{Ilochi ON, Chuemere $\mathrm{AN}^{*}$ and Olorunfemi OJ}

Department of Human Physiology, College of Health Sciences, University of Port Harcourt, Nigeria

*Corresponding author: Arthur N Chuemere, Department of Human Physiology, Faculty of Basic Medical Sciences, College of Health Sciences, University of Port Harcourt, P.M.B 5323 Choba Port Harcourt, Nigeria, Tel: +2348036776322; E-mail: arthur.nwafor@uniport.edu.ng

\section{Abstract}

Allium cepa Linn, botanicals, Liliaceae (family) commonly known as onion, and coffee are special delicacies, and conventional as functional foods that contain physiologically active ingredients that for centuries have been exploited as folk remedies for the treatment of diseases. The present study was conducted to evaluate the therapeutic efficacies and the possible participation of oxidative stress of Nigerian Allium cepa and coffee such as antioxidant, antihyperglycaemic, hypoglycaemic, hyperglycaemic in normal experimental wistar rats.

Materials and Methods: qualitative phytochemical screening of hydromethanolic extract of Allium cepa was carried out for the identifications of the phytoconstituents. Hydromethanolic extract of Allium cepa 100mg $\mathrm{kg}-1$, vitamin E 400mg kg -1, and coffee 500mg kg-1, combinations of Allium cepa and coffee and vitamin E and coffee respectively, administered orally to each group of rats daily. During the experimental periods glucose concentrations were estimated at baseline 0 (time of treatment ingestion), age 21 and 42 days respectively, with corresponded oxidative stress markers - superoxide dismutase (SOD), catalase (CAT), glutathione peroxidase (GPx), glutathione (GSH) and malondialdehyde (MDA) analyzed at age 42 days.

Results: Result ranked time-dependent (in days) glucose lowering potential of treatments as: - Allium cepa + coffee > Allium cepa > vitamin E > coffee + vitamin E; with corresponded up regulated of SOD, CAT, GPx and GSH and reduced MDA. Conversely, coffee and control group (normal rats) significantly in time - dependent, raised blood glucose level with corresponded increase in MDA with respect to other biomarkers, suggesting lipid peroxidation oxidative stress induced impairment of cellular antioxidant protective system.

Conclusion: It can be concluded that synergistic effect, presence of the additive bioactive phytoconstituents, and/or antioxidant efficacies or both, and potentiation action of several compounds in Allium cepa and coffee combined, over time, offer the intrinsic antioxidant defence system much better defensive mechanism to protect against free radicals, and alleviate the toxic effects of accumulation of reactive oxygen species (ROS); thence providing protective mechanisms against the development of elevated blood sugar levels. Evidently, Allium cepa and coffee combined is 


\section{International Journal of Biochemistry \& Physiology}

efficacious and potent hypoglycemic agent, which could be beneficial as a dietary supplement for prevention, treatment or management of raised blood glucose levels or diabetes.

Keywords: Allium cepa; Hydromethanolic extract; Oxidative stress; Coffee; Antioxidant; Hypoglycaemia; Normal rats

Abbreviations: SOD: Superoxide Dismutase; CAT: Catalase; GPx: Glutathione Peroxidase; GSH: Glutathione; MDA: Malondialdehyde.

\section{Introduction}

There is growing interest in increasing prevalence of diabetes worldwide [1]. The prevalence of diabetes (type 2 diabetes and type 1 diabetes) for all age group worldwide has been estimated as $2.8 \%$ in 2000 and $4.4 \%$ in 2030 [2]. The number of people globally with diabetes mellitus is projected to rise from 285 million in 2010 to 439 million by 2030 , a $54 \%$ increase; and $54 \%$ to more than about $54.9 \%$ million Americans between 2015 and 2030 [3,4]. More so, it has been projected that diabetes will be the seventh leading cause of death in 2030, and underscore the need for immediate and aggressive action to help prevent diabetes whenever possible in those at risk, and interventions which will be more effective in addressing the needs of people with diabetes [1].

Medicinal plants with physiologically active ingredients that for centuries have been exploited as folk remedies for treatment of diseases are gaining much importance in light of lesser side effects and cost savings opposed to orthodox methods [4-7]. Accordingly, although the minimum intake required reducing diabetes remains to be determined, Allium cepa and coffee are of physiological interest, and the use of these as therapeutic agents seems promising as their efficacy and safety is reflected by their consumption globally as vegetables and beverages.

Allium cepa, commonly known as onion, is a worldwide culinary and belonging to the family Liliaceae. It has also been used as a folk remedy for a verity of ailments/ disorders. Allium cepa has been found as a source of a complex mixture of sulphur compounds that possess bioactive properties such as quercetin, fructose, quercetin-3-glucoside, isorhamnetin-4-glucoside, xylose, galactose, glucose, mannose, organosulfur compounds, allylsulfides, flavonoids, flavenols, S-alk(en)yl cysteine sulfoxides, cycloalliin, selenium, thiosulfinates, sulfur, seleno, vitamins and some minerals [8-14]. Allium cepa has potential as an anticancer, antidiabetic, antimicrobial, antihypertensive, antioxidant [15-19].
Coffee is a common beverage used worldwide, and more recently, the potential physiological effects has been reported. Coffee contains over 1000 chemical compounds and recent studies have shown to be rich in caffeine, chlorogenic acids, diterpenes, polyphenols molecules with antioxidant properties and phytocomponents [20-22]. Coffee in the short-term has been suggested to raise blood glucose levels, and regular coffee drinking is linked to reducing the risk of diabetes [22-26]. Such information on the mechanism of coffee activity on the short-term and the long-term on blood sugar are not clear. Paucity of literature on Allium cepa, coffee or the combination of both and the association of oxidative stress whether or not could have synergistic, potentiative, antagonistic, physio-pharmacological or therapeutic efficacies, formed the basis of this study.

Oxidative stress results when the accumulation of generation of excessive oxygen-free radicals (ROS) or reactive forms of oxygen are produced faster than they can be safely neutralized by in vivo antioxidant defence mechanisms- non-enzymatic antioxidant systems, such as glutathione (GSH), malondialdehyde (MDA) and defense-related enzymes such as superoxide dismutase (SOD), catalase (CAT), and glutathione peroxidase (GPx) and /or from a weakened or impaired intrinsic antioxidant defense, with resultant formation of pathological conditions [27-29]. The aim of present study was to evaluate oxidative stress level, antihypergylcaemic activity of Allium cepa and coffee in normal experimental animal models.

\section{Materials and Methods}

\section{Plant Material}

Fresh and healthy large and pungent Allium cepa bulbs (red onion) were purchased and extracted by maceration process for $72 \mathrm{~h}$ using hydromenthanol procedure [30,31]. Qualitative or preliminary phytochemical studies revealed the presence of flavonoids, glycoside, carbohydrates, tannins, amino acid and sterols etc in Allium cepa hydromnthanolic extract.

\section{Experimental Animal and Drug Treatment}

Thirty adult wistar rats, weighing 160 to $300 \mathrm{~g}$ were obtained from the animal house, Department of Physiology. The animals were randomly divided into six (6) groups containing 5 rats per group. 


\section{International Journal of Biochemistry \& Physiology}

Hydromethanolic extract of Allium cepa $100 \mathrm{mg} \mathrm{kg}^{-1}$, Vitamin E (a known antioxidant) 400 $\mathrm{mg} \mathrm{kg}^{-1}$, and Coffee $500 \mathrm{mg} \mathrm{kg}^{-1}$, combinations of Allium cepa and coffee, and vitamin $\mathrm{E}$ and coffee respectively were administered orally to each group of rats once daily for 42 days. The control group received normal saline. Animals had free access to standard pellets as a basal diet and water ad libitum.

\section{Estimation of Blood Glucose}

Blood samples from the tail of the animals were collected at baseline 0 (time of treatment ingestion), age 21 and 42 days respectively and analyzed based on glucose oxidase-perioxidase principles using digital glucometer (ACC-CHEK Aviva glucometer) [32].

\section{Estimation of Oxidative Stress Markers}

Estimation of liver enzymatic antioxidants activity catalase (CAT), superoxide dismutase (SOD), and selenium-dependent glutathione peroxidase (GPx) and non-enzymatic antioxidants concentration reduced glutathione (GSH) and malondialdehyde (MDA) were measured by adopting the methods described and analyzed at age 42 days [33-38].

\section{Ethical Approval}

The study was approved by the Institutional animal ethics committee and all experimental procedures were carried out in strict accordance with guidelines prescribed by the committee for the purpose of control and supervision on experimentation animals. Anaesthetics were applied according to the standards given by the guide of EC Directives 86/609/EEC. Animals were anaesthetized with the administration of diethyl ether.

\section{Statistical Analysis}

Data are presented in mean \pm SEM and percentage. SPSS 20.0 are used for statistical analysis such as mean comparisons, and values are significant at $\mathrm{p} \leq 0.05$ or at confidence interval of $95 \%$.

\section{Results}

The physical inactive and sedentary control groups on super nutritional dietary intake produced in a time dependent significant $(\mathrm{p}<0.05)$ increased higher blood glucose levels with percentage increment of $32.9 \%$ at age 21 days and $33.7 \%$ at age 42 days in comparison with basal levels (Table 1).

\begin{tabular}{|c|c|c|c|c|c|c|c|}
\hline \multirow{2}{*}{$\begin{array}{c}\text { Treatments } \\
\text { (mg/kg/body weight) }\end{array}$} & \multirow{2}{*}{$\begin{array}{c}\text { day } 0 \\
(\mathrm{mmol} / \mathrm{l})\end{array}$} & \multirow{2}{*}{$\begin{array}{c}\text { day } 21 \\
\text { (mmol/l) }\end{array}$} & \multirow{2}{*}{\begin{tabular}{|c|}
$\begin{array}{c}\text { \% Relative } \\
\text { Change }\end{array}$ \\
$0 \rightarrow 21$ \\
\end{tabular}} & \multirow{2}{*}{$\begin{array}{c}\text { day } 42 \\
(\mathrm{mmol} / \mathrm{l})\end{array}$} & \multicolumn{2}{|c|}{$\begin{array}{l}\text { \% Relative } \\
\text { Change }\end{array}$} & \multirow{2}{*}{$\begin{array}{c}\text { \%overall } \\
\text { Increase/decrease } \\
\text { in blood glucose }\end{array}$} \\
\hline & & & & & $0 \rightarrow 42$ & $21 \rightarrow 42$ & \\
\hline Control (Normal saline) & $5.16 \pm 0.77$ & $6.86 \pm 0.10$ & 32.9 & $6.90 \pm 0.22$ & 33.7 & 0.58 & 0.8 \\
\hline Vitamin E400 & $5.90 \pm 0.70$ & $5.80 \pm 0.20^{*}$ & -1.69 & $5.22 \pm 0.22 *$ & -11.52 & -10 & -9.83 \\
\hline Allium cepa 100 & $5.96 \pm 0.30$ & $5.30 \pm 0.10^{*}$ & -11.0 & $4.60 \pm 0.20^{*}$ & -22.8 & -13.2 & -11.8 \\
\hline Coffee 500 & $6.12 \pm 0.40$ & $7.04 \pm 0.31 *$ & 15.0 & $7.14 \pm 0.20^{*}$ & 16.6 & 1.42 & 1.6 \\
\hline Allium cepa $100+$ Coffee 500 & $5.92 \pm 0.19$ & $6.30 \pm 0.12^{*}$ & 6.41 & $4.80 \pm 0.23^{*}$ & -18.91 & -23.8 & -25.32 \\
\hline Vitamin E400+ Coffee 500 & $5.96 \pm 0.12$ & $5.38 \pm 0.10^{*}$ & -9.73 & $5.34 \pm 0.16^{*}$ & -10.4 & -0.74 & -0.67 \\
\hline
\end{tabular}

Table 1: Time-dependent effect of Allium cepa, coffee and vitamin E on blood glucose level.

Correspondingly, at age 42 days, control groups produced significant decreased enzymatic antioxidant activities of supraoxide dismutase (SOD), catalase (CAT), glutathione peroxidase (GPx) and non-enzymatic antioxidant reduced glutathione (GSH) by $90.8 \%$, 9.82\%, 7.8\% and 49.1\% respectively, and increased malondialdehyde (MDA), a marker of lipid peroxidation due to oxidative stress, by $21.5 \%$, in comparison with positive control (vitamin E)(Tables $2 \& 3$, role 2). Table 2 column 3 also gives supraoxide dismutase (SOD) ratio, $\mathrm{R}$, to control group (normal rats). Table 1 (columns 7 and 8) also gives percentage increment in blood glucose level between ages 21 to 42 days and the overall increment after age 42 days

The treatment with combination of Allium cepa and coffee, Allium cepa and Vitamin E, and combination of vitamin E and Allium cepa produced significant time dependent overall percentage decreased blood glucose concentration of 25.32, 11.8, 9.83, and 0.67 after age 42 days respectively (Table 1 column 8), with corresponded increased SOD, CAT, GPx, and GSH and decreased MDA in comparison with control group (normal rats) or positive control (vitamin E) (Tables 2 \& $3)$. 


\section{International Journal of Biochemistry \& Physiology}

\begin{tabular}{|c|c|c|c|c|c|c|c|c|c|}
\hline \multirow{2}{*}{$\begin{array}{l}\text { Treatments } \\
\text { (mg/kg /body } \\
\text { weight) }\end{array}$} & \multirow{2}{*}{$\begin{array}{c}\text { Supraoxide } \\
\text { Dismutase } \\
\text { (u/ml) }\end{array}$} & \multirow{2}{*}{$\begin{array}{c}\text { Ratio of } \\
\text { SOD } \\
\text { relative to } \\
\text { control }\end{array}$} & \multirow{2}{*}{\begin{tabular}{|l|}
$\begin{array}{c}\text { \%Relative } \\
\text { Change to }\end{array}$ \\
Vitamin E \\
\end{tabular}} & \multirow{2}{*}{$\begin{array}{c}\text { Catalase } \\
(\mathrm{u} / \mathrm{g})\end{array}$} & \multicolumn{2}{|c|}{$\begin{array}{l}\text { \%Relative } \\
\text { Change to }\end{array}$} & \multirow{2}{*}{$\begin{array}{c}\text { Glutathione } \\
\text { Peroxidase } \\
(\mu \mathrm{g} / \mathrm{ml})\end{array}$} & \multicolumn{2}{|c|}{$\begin{array}{l}\text { \%Relative } \\
\text { Change to }\end{array}$} \\
\hline & & & & & ol & $\begin{array}{c}\text { Vitamin } \\
E\end{array}$ & & Control & $\begin{array}{c}\text { Vitamin } \\
\text { E }\end{array}$ \\
\hline Control & $21.7 \pm$ & 1 & -90.8 & $202.0 \pm 15.93$ & 0 & -9.82 & 29.4 & 0 & -7.83 \\
\hline Vitamin E 400 & $237.2 \pm 20.13^{*}$ & 1:11 & 0 & $224.0 \pm 32.75^{*}$ & 10.8 & 0 & $31.9 \pm 4.43 *$ & 8.5 & 0 \\
\hline Allium & $337.3 \pm 23.20 *$ & + & 42.2 & 230.0 & $13 . \varepsilon$ & 2.67 & $38.9=$ & 32.3 & 21.9 \\
\hline Coffee500 & 121.5 & 1:06 & 7 & 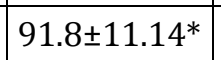 & -54.5 & -59 & 20.2 & -31.2 & -36.6 \\
\hline $\begin{array}{c}\text { Allium cepa } \\
100+\text { coffee } 500\end{array}$ & $487.6 \pm 46.22 *$ & $1: 23$ & 105.5 & $220.0 \pm 19.40 *$ & 8.91 & -1.78 & $42.0 \pm 5.04 *$ & 42.8 & 31.6 \\
\hline $\begin{array}{c}\text { Vitamin E 400 + } \\
\text { coffee } 500\end{array}$ & $457.6 \pm 32.8^{*}$ & $1: 21$ & 92.9 & $206.0 \pm 29.80 *$ & 1.98 & -8.03 & $32.9 \pm 6.44 *$ & 11.9 & 3.13 \\
\hline
\end{tabular}

Table 2: Allium cepa, coffee and vitamin E effects on enzymic markers

\begin{tabular}{|c|c|c|c|c|c|c|}
\hline \multirow{2}{*}{ Treatments } & \multirow{2}{*}{ Malondialdehyde } & \multicolumn{2}{|c|}{$\%$ Relative change to } & \multirow{2}{*}{$\begin{array}{c}\text { Reduced Glutathione } \\
(\mu \mathrm{g} / \mathrm{ml})\end{array}$} & \multicolumn{2}{|c|}{$\%$ Relative change to } \\
\hline & & Control & Vitamin E & & Control & Vitamin E \\
\hline Control (Normal saline) & $97.51 \pm 6.88$ & $\mathbf{0}$ & 21.5 & $11.9 \pm 0.84$ & $\mathbf{0}$ & -49.1 \\
\hline Vitamin E 400 & $80.2 \pm 18.46^{*}$ & -17.7 & $\mathbf{0}$ & $23.4 \pm 1.33^{*}$ & 96.6 & $\mathbf{0}$ \\
\hline Allium cepa 100 & $73.9 \pm 16.80 *$ & -24.2 & -7.85 & $28.0 \pm 15.6 *$ & 135.2 & 19.6 \\
\hline Coffee 500 & $156.1 \pm 21.0^{*}$ & 60.08 & 94.6 & $9.1 \pm 1.90^{*}$ & -23.5 & -61.1 \\
\hline $\begin{array}{c}\text { Allium cepa100 + coffee } \\
500\end{array}$ & $74.7 \pm 3.70^{*}$ & -23.7 & -7.23 & $19.2 \pm 1.33^{*}$ & 61.3 & -17.9 \\
\hline $\begin{array}{c}\text { Vitamin E 400+ coffee } \\
500\end{array}$ & $86.4 \pm 10.80 *$ & -11.3 & 7.7 & $10.6 \pm 0.90^{*}$ & -10.9 & -54.7 \\
\hline
\end{tabular}

Table 3: Allium cepa, coffee and vitamin E effects on non- enzymic markers

Table 1(column 7) also depicts percentage increment in blood glucose level between ages 21 to 42 days for the various treatments.

Coffee treatment similar to control (normal rats) provoked gradual increase in blood glucose level over time (in days) (Table 1, role 5), with corresponded significant decreased SOD, CAT, GPx, and GSH and increased MDA (Tables 2 and 3 columns 5). Table 1 (role 5 columns 7 \& 8) also depicts percentage increment in blood glucose level between ages 21 to 42 days and after 42 days for the treatment.
Table 4 compared time-dependent inter group percentage relationship change in blood glucose modulation by the various treatments in comparison with control group (normal rats) and vitamin E. The table shows that coffee group and normal rats produced significant increased blood glucose levels while Allium cepa lowers. Meanwhile, administration of the combination of Allium cepa and coffee produced raised blood glucose levels after day 21 which was significantly reduced to a point below that produced in the positive control group after 42 days; while coffee and vitamin E similarly produced raised blood glucose levels after day 42 (Table 4 role 6 and 7).

\begin{tabular}{|c|c|c|c|c|}
\hline \multirow{3}{*}{ Treatment groups } & \multicolumn{4}{|c|}{ Time-dependent (in days) percentage change in blood glucose level relative to: } \\
\hline & \multicolumn{2}{|c|}{ Control } & \multicolumn{2}{|c|}{ Vitamin E } \\
\hline & Day 21 & Day 42 & Day 21 & Day 42 \\
\hline Control (normal saline) & $\mathbf{0}$ & $\mathbf{0}$ & 18.2 & 32.1 \\
\hline Vitamin E & -15.4 & -24.3 & $\mathbf{0}$ & $\mathbf{0}$ \\
\hline Allium cepa & -22.7 & -33.3 & -8.6 & -11.8 \\
\hline Coffee & 2.62 & 3.47 & 21.3 & 36.7 \\
\hline Allium cepa + Coffee & -18.1 & -30.4 & 8.62 & -8.04 \\
\hline Allium cepa+ Vitamin E & -21.7 & -22.6 & -7.24 & 2.29 \\
\hline
\end{tabular}

Table 4: Time-dependent Inter group percentage relationship change in blood glucose level 


\section{International Journal of Biochemistry \& Physiology}

\section{Discussion}

The present study was conducted to investigated time - dependent (in days) hypoglycaemic potential of Allium cepa, coffee, vitamin E (which also acts as antioxidant) as well as the combination of coffee and Allium cepa or vitamin E and Allium cepa on blood sugar level, with corresponded levels of antioxidant defence mechanisms/oxidative stress markers (SOD, MDA, CAT, GPx, GSH) in normal experimental rats. The results were compared with control group (normal rats) and positive control group (vitamin E) respectively; however, the changes in the parameters studied were within physiological normal range.

Physical inactive and sedentary lifestyles can be viewed as stressors which can lead to oxidative cellular damage, likely due to enhanced production of ROS induced release of toxic non-enzymatic metabolite, MDA, a marker of end products of the lipid peroxidation process associated with pathological conditions [27-29]. In the present study, the control group (normal rats) produced significant $(\mathrm{p}<0.05)$ hypergylcaemic activity $(33.7 \%)$ by raising blood glucose levels above the basal levels (day 0) at age 42 days, with corresponded decreased SOD, CAT, GPx and GPH and increased MDA, with respect to positive control (vitamin E). Such effects were also evidently noted during coffee administration (see below) where there was the development and progression of raised blood glucose levels precisely in agreement with the view of an increased association of MDA, a marker of lipid peroxidation with oxidative vascular injury [39-47]. Our observation is also in support of the view that lack of regular physical activity predisposes to raised blood sugar level or onset of type 2 diabetes [1]. Furthermore, the observed molecular perturbation perhaps may also cause impairment of TRPM2 (transport receptor potential cation channel melastatin-related subfamily member 2) channel which plays a critical role in mediating oxidative-stressinduced cell death, thereby, contributing to the pathogenesis of higher blood glucose level. In contrast to the present findings, some studies have reported that plasma postprandial glucose level of control group (normal rats) showed a negligible change during the experimental period $[8,48]$. However, these were largely studies at age 15 days. Other studies have suggested that exercise of sufficient intensity or duration can promote increase in free radical production which may overwhelm antioxidant defence. Post-intensive bout of physical exercise resulted in an up regulation in MDA, CAT and GPx than at rest or at pre-physical exercise; which CAT and GPx possibly offered protection from ROS tissue damage [49]. This is in contrast to the findings of this study in that dynamic equilibrium did not exist between oxygen consumption and ROS production.
As the results have shown, Allium cepa (onion) gradually and significantly $(\mathrm{p}<0.05)$ reduced the blood glucose levels to a point below that produced in the negative control group after 42 days (Table 1) with corresponded up regulation of GSH, CAT, SOD, and GPx and reduction in MDA (Tables 2 and 3 ). This is evident that the association probably reflects a possible mechanistic links with bioactive constituents and antioxidant potential of Allium cepa capable of modulating biomarkers of lowered blood glucose levels. Precisely, our observation supports the report in which was stated that Allium cepa acts as a hypoglycemic agent by mechanisms rather than increasing insulin levels having extra pancreatic effects; acting directly on tissues as liver, muscles etc. and alter the activities of the regulatory enzymes of glycolysis, gluconeogenesis and other pathways $[7,50,51]$. Other studies reported that antihyperglycaemic efficacy of Allium cepa is brought about by the antioxidant properties of its essential oil components through suppression of oxidative stress, thereby preventing hyperglycaemia [52]. Nevertheless, our findings that Allium cepa have glucose lowering properties, and may be beneficial to those with diabetes in view of its safety as reflected by its worldwide use as vegetable collaborate with others [7,53-56].

Coffee, in the short- term, has been reported to produce increased blood sugar level; and some studies showed that over time, drinking coffee actually led to a decrease in blood sugar levels, including a reduced risk of type 2 diabetes [23,57-62]. Meanwhile, the exact mechanism that governs the physiological regulation of coffee induced short-term production of raised blood sugar level, but significantly lower in the long term is still unclear. The result of the present study showed that coffee produced a time - dependent raised blood glucose level with significant $(\mathrm{p}<0.05)$ hyperglycaemic activity (15\% and 16.6\%) at age 21 and 42 days respectively; with corresponded decreased SOD, CAT, GPx, and GSH and increased MDA, in comparison to control group (normal rats) or positive control (vitamin E). We also established decreased supraoxide dismutase (SOD) ratio, $\mathrm{R}$, to control group (normal rats) and ranked as: coffee < vitamin $\mathrm{E}<$ Allium cepa $<$ vitamin $\mathrm{E}+$ coffee $<$ Allium cepa + coffee (Table 2 column 3). Interrelationship between decreased ratio, $R=$ SOD/control group (1:6) versus the lipid peroxidation oxidative stress biomarker, MDA (1:2) was observed. The levels of MDA were significantly elevated suggesting possibly adverse association of coffee with biomarkers for hyperglycaemic induced oxidative cellular damage. Nonetheless, the observation that coffee produces raised blood glucose level support the findings by others in which it was stated that the hormone adrenaline plays an important role in shortterm coffee induced raised blood glucose levels [62]. 


\section{International Journal of Biochemistry \& Physiology}

We have also demonstrated that Allium cepa and coffee combined showed gradual and significant decrease in blood glucose levels (from 6.41\% at age 21 days to $18.91 \%$ at age 42 days) with corresponding decrease in MDA (23.7\%) compared to normal rats, suggesting that the combination of Allium cepa and coffee also did not provoke oxidative stress. Combination of Allium cepa and coffee showed significant antihyperglycaemic activity $(23.8 \%$ or $25.32 \%$ ) by bringing down blood glucose level at age between 21 to 42 days or at age 42 day in comparison to Allium cepa alone. This was evident that the different components present in Allium cepa and coffee probably have additive mechanistic actions that may exact synergetic effects and potentiate suppression of oxidative stress, thereby lower blood glucose level. Thus, the combination of coffee and Allium cepa possibly offers the intrinsic antioxidant defence system much better defensive mechanism to protect against free radicals and alleviate the toxic effects of accumulation of reactive oxygen species (ROS) than Allium cepa alone. Our result is in support that the combinations of antioxidants are capable of improving intrinsic antioxidant status and can help in the prevention and postponing the onset of the pathogenesis of vascular damage [47].

The effect of vitamin E, a non-enzymatic antioxidant, which protects the tissues from the ill effects of oxidative stress, on blood glucose in the animal models, was also studied. Similar to the effect of Allium cepa alone, vitamin $\mathrm{E}$ group or the groups administer the combination of vitamin $\mathrm{E}$ and coffee did not also seem over time, to make blood sugar levels higher in comparison with control group (normal rats). Combination of Allium cepa and coffee (blood glucose level 25.32\% and MDA 23.7\%) and Allium cepa alone (blood glucose level 11.8\% and MDA 24.2\%) produced much better blood sugar lowering effects as well as the oxidative stress biomarkers, in comparison with the combination of vitamin $\mathrm{E}$ and coffee (blood glucose level 0.67\%; and both MDA 11.3\% and GSH, 10.9\%) and vitamin E alone (blood glucose level 9.83\%; and MDA $17.7 \%$ ) at age 42days. These discrepancies may plausibly be due to antagonist association of the bioactive constituents and antioxidant potential of coffee and vitamin $\mathrm{E}$ and/or to hydrophobic characteristics of vitamin $\mathrm{E}$ being contrary to hydrophilic enzyme antioxidant system or both, thereby, suppressing the development of antihyperglycaemic activities.

Our results further showed an increase in blood glucose level following administration of the combination of Allium cepa and coffee (8.62\%) after the first 21 days, and in the combination of vitamin $\mathrm{E}$ and coffee (2.29\%) after 42 days, in comparison with positive control (vitamin E) (Table 4). These may be a reflection of the glucogenic effects of the combinations of coffee and Allium cepa or coffee and vitamin E, which perhaps may counteract the common side effects, hypoglycemia of many anti-diabetic agents. Previous studies have reported an increase in blood glucose level after the first 4 hour following Allium cepa administration, and which was attributed to the glucogenic effects of Allium cepa [7].

\section{Conclusion}

It can be concluded that the combination of Allium cepa and coffee, over time, significantly lowers blood sugar level possibly due to synergistic effect, the presence of the additive bioactive phytoconstituents, and/or antioxidant efficacies or both, and potentiation action of several compounds over Allium cepa alone, combinations of Allium cepa and vitamin E or coffee and vitamin $\mathrm{E}$. This mechanistic links offer the intrinsic antioxidant defence system much better defensive mechanism to protect against free radicals, and alleviate the toxic effects of accumulation of reactive oxygen species (ROS), thereby, providing protective mechanisms against the development of raised blood glucose levels. It is evident that Allium cepa and coffee combined produced significant hypoglycaemic effects which could be beneficial as a dietary supplement for the prevention and/or care of diabetes.

\section{References}

1. WHO (2017) Diabetes Fact sheet.

2. Wild S, Roglic G, Anders Green A, Sicree R, King H (2004) Global Prevalence of Diabetes: Estimates for the year 2000 and projections for 2030. Diabetes Care 27(5): 1047-1053.

3. Chen L, Magliano DJ, Zimmet PZ (2012) The worldwide epidemiology of type 2 diabetes mellitus - present and future perspectives. Nat Rev Endocrinol 8(4): 228-236.

4. Rowley WR, Bezold C, Arikan Y, Byrne E, Krohe S (2017). Diabetes 2030: Insight from yesterday, today and future trends. Popul Health Manag 20(1): 6-12.

5. Thakare VN, Kothavade PS, Dhote VV , Avinash D (2009) Antifertility Activity of Ethanolic Extract of Allium cepa Linn in Rats. Inter J Pharm Tech Res 1(1): 73-78.

6. Ogunmodede OS, Saalu LC, Ogunlade B, Akunna GG, Oyewopo AO (2012) An Evaluation of the Hypoglycemic, Antioxidant and Hepatoprotective Potentials of Onion (Allium cepa L.) on Alloxaninduced Diabetic Rabbits. International Journal of Pharmacology 8: 21-29. 


\section{International Journal of Biochemistry \& Physiology}

7. Eldin IMT, Ahmed EM, Abd Elwahab HM (2010) Preliminary study of the clinical hypoglycemic effects of allium cepa (Red onion) in type 1 and type 2 diabetic patients. Environ Health Insights 4: 7177.

8. Husni A, Purwanti D, Ustadi (2016) Blood glucose level and lipid profile of streptozotocin induced diabetes rats treated with sodium aliginate from Sargassium crassifolium. J Biol Sci 16(3): 58-64.

9. Boyle SP, Dobson VL, Duthie SJ, Kyle JA, Collins AR (2000) Absorption and DNA protective effects of flavonoid glycosides from an onion meal. Eur J Nutr 39(5): 213-223.

10. Heber D, Bowerman S (2001) Applying science to changing dietary patterns. J Nutr 131(11): 3078S3081S.

11. Griffiths G, Trueman L, Crowther T, Thomas B, Smith B (2002) Onions--a global benefit to health. Phytother Res 16(7): 603-615.

12. Lanzotti V (2006) The analysis of onion and garlic. J Chromatogr A 1112(1-2): 3-22.

13. Arnault I, Auger J (2006) Seleno-compounds in garlic and onion. J Chromatogr A 1112(1-2): 23-30.

14. Rose P, Whiteman M, Moore PK, Zhu YZ (2005) Bioactive S-alk(en)yl cysteine sulfoxide metabolites in the genus Allium: the chemistry of potential therapeutic agents. Nat Prod Rep 22(3): 351-368.

15. Hubbard GP, Wolffram S, de Vos R, Bovy A, Gibbins JM (2006) Ingestion of onion soup high in quercetin inhibits platelet aggregation and essential components of the collagen-stimulated platelet activation pathway in man: a pilot study. Br J Nutr 96(3): 482-488.

16. Galal EE, Gawad MA (1965) Antidiabetic activity of Egyptian onion "Allium cepa" extract. J Egypt Med Assoc 48(Suppl): 14-45.

17. Dhanprakash, Brahma N, Garima SU (2007) Antioxidant and free radical scavenging activities of phenols from onion (Allium cepa). Food Chemistry 102(4): 1389-1393.

18. Sakai Y, Murakami T, Yamamoto Y (2003) Antihypertensive effect of onion on NO synthase inhibitor induced hypertensive rats. Biosc Biotecnol Biochem 67(6): 1305-1311.

19. Compos KE, Diniz YS, CataneoAC, Faine LA, Alves MJ, et al. (2003) Hypoglycemic and antioxidant effect of onion, Allium cepa: diatary onion addition, antioxidant activity and hypoglycic effect on diabetic rats; Int J Food Sci Nutr 54(3): 241-246.

20. Votto APS, Domingues BS, de Souza MM, da Silva Júnior FMR, Caldas SS, et al. (2010) Toxicity mechanisms of onion (Allium cepa) extracts and compounds in multidrug resistant erythroleukemic cell line Biol Res 43(4): 429-437.

21. Nuhu AA (2014) Bioactive micronutrients in coffee: recent analytical approaches for characterization and quantification. Nutrition 2014: 1-13.

22. Cano-Marquina A, Tarin JJ, Cano A (2013) The impact of coffee on health. Maturitas 75(1): 7-21.

23. Adriana F (2012) Coffee Constituents: Emerging Health Effects and Disease Prevention. $1^{\text {st }}$ (Edn.), YiFang Chu (Ed), John Wiley \& Sons, Inc, Blackwell Publishing Ltd.

24. Huxley R, Lee CM, Barzi F, Timmermeister L, Czernichow S, et al. (2009) Coffee, decaffeinated coffee, and tea consumption in relation to incident type 2 diabetes mellitus: a systematic review with meta-analysis. Arch Intern Med 169(22): 2053 2063.

25. Whitehead N, White H (2013) Systematic review of randomised controlled trials of the effects of caffeine or caffeinated drinks on blood glucose concentrations and insulin sensitivity in people with diabetes mellitus. J Hum Nutr Diet 26(2): 111125.

26. Jacobs S, Kröger J, Floegel A, Boeing H, Drogan D, wt al. (2014) Evaluation of various biomarkers as potential mediators of the association between coffee consumption and incident type 2 diabetes in the EPIC-Potsdam Study. Am J Clin Nutr 100(3): 891-900.

27. Guemouri L, Artur Y, Herbeth B, Jeandel C, Cuny G, et al. (1991) Biological variability of superoxide dismutase, glutathione peroxidase, and catalase in blood. Clin Chem 37(11): 1932-1937.

28. Ahmed RG (2005) Is there a balance between oxidative stress and antioxidant defense system during development. Med J Islam World Acad Sci 15(2): 55-63

29. Bland JS (2009) Oxidants and Antioxidants in Clinical Medicine: Past, Present and Future Potential. J Nutr Environ Med 5(3): 255-280.

30. Iwuji SC, Nwafor A, Egwurugwu J, Ejeka $\mathrm{K}$ and Akpan U (2013) Comparative characterization of phytomedical constituents of cnidoscolus 


\section{International Journal of Biochemistry \& Physiology}

aconitifolius leaf extracts. Am J Pharm Tech Res 3(1): 779-784.

31. Nwafor A, Nworah CD, and Adienbo MO (2015) High-performance thin-layer chromatography (HPTLC) fingerprint profile of hydromethanolic chloroform extract of Xylopia Aethiopica (Dunal) A. Rich (Annonaceae) fruits. BMR Phytomedicine 1(1): 1-8.

32. Trinder P (1969) Determination of glucose in blood using glucose oxidase with an alternative oxygen acceptor. Ann Clin Biochem 6: 24-27.

33. Beutler E, Duron O, Kelly BM (1963) Improved method for the determination of blood glutathione. J Lab Clin Med 61: 882-888.

34. Hafeman DG, Sunde RA, Hoekstra WG (1974) Effect of dietary selenium on erythrocyte and liver glutathione peroxidase in the rat. J Nutr 104(5): 580-587.

35. Horn HD (1963) Glutathione reductase. In: Bergmayer HU (Ed), Method in Enzymatic Analysis. New York: Academic Press, pp: 875-879.

36. Sinha KA (1972) Colorimetric assay of catalase. Anal Biochem 47(2): 389-394.

37. Mishra HP, Fridovich I (1972) The role of superoxide anion in the auto-oxidation of epinephrine and simple assay for superoxide dismutase. J Biol Chem 247(10): 3170-3175.

38. Dousset JC, Trouilh M, Foglietti MJ (1983) Plasma malondialdehyde levels during myocardial infarction. Clin Chim Acta 129(3): 319-322.

39. Rukmini MS, D'Souza B, D'Souza V (2004) Superoxide dismutase and catalase activities and their correlation with malondialdehyde in schizophrenic patients. Indian J Clin Biochem 19(2): 114-118.

40. Noberasco G, Odetti P, Boeri D, Maiello M, Adezati L (1991) Malondialdehyde (MDA) level in diabetic subjects. Relationship with blood glucose and glycosylated hemoglobin. Biomed Pharmacother 45(4-5): 193-196.

41. Mandal B, Bandyopadhyay R, Chakrabarti S, Bandyopadhyay TK (2010) Assessment of oxidative stress in patients if diabetes mellitus with and without complications. J Ind Acad Clin Med 11(1): 20-25.

42. Pazdro A, Burgess JR (2010) The role of vitamin E and oxidative stress in diabetes complication. Mech Ageing Dev 131(4): 276-286.
43. Sayed AA, Aldebasi Y, Abd-allah SO, ElGendy SM, Mohamed AS, et al. (2013) Molecular and biochemical study of superoxide dismutase gene polymorphisms in Egyptain patients with type 2 diabetes mellitus with and without retinopathy. $\mathrm{Br} J$ Med Med Res 3(4): 1258-1270.

44. Aouacheri O, Saka S and Krim M, Messaadia A, Maidi I (2015) The investigation of the oxidative stressrelated parameters in type 2 diabetes mellitus. Can J Diabetes 39(1): 44-49.

45. Verma MK, Singh SP, Alam R and Verma P (2016) Comparative Study on MDA, SOD and HbA1c Levels in Patients of Type 2 Diabetes Mellitus with Retinopathy and without Retinopathy. Int J Pharm Sci Res 7(10): 4184-4190.

46. Aziz AS, Kalekar MG, Suryakar AN, Kale R, Benjamin $\mathrm{T}$, et al. (2017) Assessment of some biochemical oxidative stress markers in type II daiabetics and non-diabetics with chronic periodontitis. Inter J Biochem Res Rev 18(2): 1-9.

47. Ganjifrockwala FA, Joseph JT, George G (2017) Serum total superoxide dismutase enzyme activity in type 2 diabetic patients with retiopathy in mthatha region of the Eastern cape Province of South Africa. Biom Res 28(2): 532-538.

48. Jalees SS, Rosaline M (2017) Study of malondialdehyde and estimation of blood glucose levels in patients with diabetes mellitus with cataract. Inter J Clin Biochem Res 4(3): 319-323.

49. Jiang LH (2017) Oxidative stress is harmful, and the TRPM2 channel bears part of the responsibility. Physiology news 108: 36-39.

50. Shukia R, Sharma SB, Puri D, Prabhu KM, Murthy PS (2000) Medicinal plants for treatment of diabetes mellitus. Indian J Clin Biochem 15(1): 169-177.

51. Bhushan S (1984) Effect of oral administration of raw onion on glucose tolerance test of diabetics: a comparison with tolbutamide. Curr Med Pract 28: 712-715.

52. Ebele KJ, Jennifer IA, Nnabugo EC, Sidney OI Chibuike OK, et al. (2016) Oxidative stress/lipid peroxidation and antioxidant enzymes in apparently healthy individuals involved in physical exercise. A J Med Sci 7(6): 16-19.

53. El-Soud NA, Khalil M (2010) Antioxidative effects of Allium Cepa essential oil in streptozotocin induced diabetic rats. Maced J Med Sci 3(4): 344-351.

54. Sharma KK, Gupta RK, Gupta S, Samuel KC (1977) Antihyperglycemic effect of onion: effect on fasting 


\section{International Journal of Biochemistry \& Physiology}

blood sugar and induced hyperglycemia in man. Indian J Med Res 65(3): 422-429.

55. Tjokroprawiro Pikir BS, Budhiarta AA, Pranawa, Soewondo H, et al. (1983) Metabolic effects of onion and green beans on diabetic patients. Tohoku J Exp Med 141(Suppl): 671-676.

56. Srinivasan K (2005) Plant foods in the management of diabetes mellitus: spices as beneficial antidiabetic food adjuncts. Int J Food Sci Nutr 56(6): 399-414.

57. Ojieh AE, Ugorji AE, Ovuakporaye IS, Ewhre OL, Ossai NR (2015) Comparative Evaluation of Hypoglycemic Properties of Raw And Boiled Allium cepa in Alloxan-Induced Diabetes Mellitus Rats. UK Journal of Pharmaceutical and Biosciences 4(3): 3844.

58. Bhupathiraju SN, Pan A, Malik VS, Manson JE, Willett WC, et al. (2013) Caffeinated and caffeinefree beverages and risk of type 2 diabetes. Am J Clin Nutr 97(1): 155-166.
59. Ding M, Bhupathiraju SN, Chen M, van Dam RM, Hu FB (2014) Caffeinated and decaffeinated coffee consumption and risk of type 2 diabetes: a systematic review and a dose-response metaanalysis. Diabetes care 37(2): 569-856.

60. Koloverou E, Panagiotakos DB, Pitsavos C, Chrysohoou C, Georgousopoulou EN, et al. (2015) The evaluation of inflammatory and oxidative stress biomarkers on coffee-diabetes association: results from the 10-year follow-up of the ATTICA Study(2002-2012). Eur J Clin Nutr 69(11): 12201225.

61. Bhaktha G, Nayak BS, Mayya S, Shantaram M (2015) Relationship of Caffeine with Adiponectin and Blood Sugar Levels in Subjects with and without Diabetes. J Clin Diagn Res 9(1): BC01-3.

62. Zaharieva DP, Riddell MC (2013) Caffeine and glucose homeostasis during rest and exercise in diabetes mellitus. Appl Physiol Nutr Metab 38(8): 813-822. 